\title{
Método e discurso filosófico no diálogo 0 Sofista de Platão
}

\author{
Method and philosophical discourse in Plato's dialogue Sophist
}

$10.21680 / 1983-2109.2021 \mathrm{v} 28 \mathrm{n} 57 \mathrm{ID} 24084$

\author{
Alexandre Alves \\ Universidade Federal do Rio Grande do Sul (UFRGS) \\ 0000-0002-0810-650X \\ sandoralves@gmail.com
}

\begin{abstract}
Resumo: Por sua discussão da questão do não-ser e por sua intenção de fundamentar o discurso filosófico, o diálogo Sofista ocupa uma posição central na história da filosofia. O objetivo deste artigo é relacionar o método de definição empregado por Platão no diálogo Sofista (a diérese) com sua concepção do discurso filosófico. As diferentes definições para o sofista propostas no diálogo não são somente parte da polêmica de Platão contra a sofística, mas fundamentam a própria concepção platônica do filósofo e do discurso filosófico. Enquanto a dialética seria o método empregado pelo filósofo para chegar ao conhecimento e à sabedoria, a sofística seria apenas imitação do verdadeiro conhecimento e da verdadeira sabedoria.
\end{abstract}

Palavras-chave: Sofística; Ontologia; Dialética.

Abstract: Due to its discussion of the question of non-being and its intention of grounding the philosophical discourse, Plato's dialogue The Sophist occupies a central position in the history of philosophy. The purpose of this article is to relate the definition method used by Plato in the dialogue (the diaeresis) with his conception of philosophical discourse. The different definitions for the sophist proposed in the dialogue are not only part of Plato's polemic against sophistry, but underpin the very Platonic conception of the philosopher and philosophical discourse. While dialectics would be the method employed by the philosopher to arrive at knowledge and wisdom, sophistry would be only an imitation of true knowledge and true wisdom.

Key words: Sophistic; Ontology; Dialectics

\section{INTRODUÇÃO}

O objetivo deste texto é relacionar o método de definição empregado por Platão no diálogo Sofista com sua concepção do discurso filosófico. O texto foi dividido em três partes. Na primeira parte, parto de algumas considerações gerais sobre a interpretação dos diálogos de Platão para contextualizar o diálogo Sofista na obra do filósofo. Em seguida, examino o método da diérese e as seis definições iniciais do sofista no diálogo. Na segunda parte, apresento a questão central do diálogo - o problema do não-ser - e como a solução desse problema permite que Platão fundamente sua concepção do discurso filosófico, demonstrando que o 
discurso verdadeiro sobre o ser é possível. Nesta parte, exponho brevemente a tese de Parmênides sobre o ser e o ponto de vista de Protágoras como representativo da tese sofística sobre ser e discurso. Por fim, na terceira parte, retomo a definição do sofista para contrastá-la com a definição platônica do filósofo. Enquanto a dialética seria o método empregado pelo filósofo para chegar ao conhecimento e à sabedoria, a sofística seria apenas imitação do verdadeiro conhecimento e da verdadeira sabedoria.

\section{NOTA SOBRE A FINALIDADE DOS DIÁlOGOS DE PLATÃo}

Segundo Victor Goldschmidt, na interpretação de textos filosóficos, é essencial distinguir entre tempo histórico e tempo lógico. A especificidade do discurso filosófico, em relação a outras criações do espírito humano, é o movimento dialético em que distintas teses se contrapõe por meio da argumentação racional, que oferece razões para justificar uma posição ou se contrapor a outras. Assim, a boa interpretação deve conjugar a investigação do contexto histórico de um sistema filosófico com o exame da ordem das razões internas das próprias obras. Assim, na opinião de Goldschmidt, reduzir a obra ao contexto que a viu nascer é tão equivocado quanto reduzi-la à análise puramente lógica, fazendo tábula rasa de suas determinações históricas:

A filosofia é explicitação e discurso. Ela se explicita em movimentos sucessivos, no curso dos quais produz, abandona e ultrapassa teses ligadas umas às outras numa ordem por razões. A progressão (método) desses movimentos dá à obra escrita sua estrutura e efetua-se num tempo lógico. A interpretação consistirá em reapreender, conforme a intenção do autor, essa ordem por razões e em jamais separar as teses dos movimentos que as produziram (Goldschmidt, 1970, p. 140).

A forma específica que assume esse movimento no pensamento de Platão é o diálogo. Muitos diálogos platônicos são inconclusivos ou aporéticos, estendemse demasiadamente sobre aspectos secundários de um tema ou examinam insuficientemente esse tema. O fato é que, para veicular sua filosofia, Platão escolheu a forma dialógica ao invés do discurso dogmático ou do tratado. Reduzir um diálogo de Platão a um conjunto de teses e premissas logicamente articuladas, abstraindo da forma dialógica, significaria ignorar o ponto central da concepção platônica da filosofia.

Pierre Hadot afirma que o objetivo dos diálogos platônicos não é "informar", mas "formar" o leitor, que deve se imaginar no lugar dos interlocutores do diálogo:

Sua filosofia não consiste em construir um sistema teórico da realidade e em "informar" imediatamente seus leitores escrevendo um conjunto de diálogos que expõe metodicamente esse sistema, mas consiste em "formar", isto é, em transformar os indivíduos, fazendo-os experimentar, no exemplo do diálogo ao qual o leitor tem a 
ilusão de assistir, as exigências da razão e, finalmente, a norma do bem (Hadot, 1999, p.113).

Hadot enfatiza que a dialética platônica, exemplificada nos diálogos, não é nem um exercício puramente lógico, destinado a ensinar as regras técnicas da argumentação precisa, nem uma luta entre dois indivíduos, em que o mais habilidoso impõe seu ponto de vista ao outro. O diálogo deve ser visto como um esforço em comum de dois interlocutores que se submetem às exigências racionais do discurso verdadeiro (lógos) para, desta forma, transcender seus próprios pontos de vista limitados. O diálogo platônico, portanto, pressupõe uma ética discursiva, que tem como principal pressuposto a boa vontade em dialogar para formar-se e buscar a verdade em conjunto ao invés de apenas contraargumentar para vencer uma disputa. O diálogo, portanto, é a essência da concepção platônica da filosofia.

\section{AS DEFINIÇÕES DO SOFISTA E O MÉTODO DA DIÉRESE}

O Sofista é um dos diálogos da fase tardia de Platão, em que ele expõe suas próprias doutrinas ontoepistemológicas ao invés de adotar o ponto de vista socrático que caracterizava seus diálogos anteriores. O Sofista faria parte de uma tríade de diálogos, que incluiria também o Político e um diálogo nunca escrito chamado o Filósofo. 1 Tanto no Sofista quanto no Político, Sócrates tem apenas um papel secundário; em ambos, o interlocutor principal é o Estrangeiro de Eleia. A escolha do nome é uma possível indicação de que Platão está acertando contas com a ontologia de Parmênides para fundamentar sua própria doutrina das formas.

No Sofista, Platão adota um método de definição distinto dos diálogos anteriores. Em 218c-e, o Estrangeiro propõe que se adote um paradigma, pois é preciso "ensaiar exemplos pequenos e mais fáceis antes de chegar propriamente aos temas grandiosos" (218d). O paradigma escolhido é o pescador com anzol e a tarefa nesse momento do diálogo é definir a que gênero pertence a arte do pescador. Então começam as divisões dicotômicas do método dierético 2. As artes são divididas em

\footnotetext{
${ }^{1}$ Segundo M. L. Gill (2020, p. 3): “Se o Sofista e o Político são exercícios filosóficos, pode haver uma boa razão pela qual o diálogo final da trilogia, o Filósofo, está faltando. Platão estragaria a lição se ele o escrevesse para nós. Se aprendemos como investigar problemas filosóficos no Sofista e no Político, Platão pode estar desafiando sua audiência a procurar por si mesma pelo filósofo, usando as técnicas e recomendações que estes diálogos fornecem."

${ }^{2}$ No Léxico de Platão, Michael Schramm assim define o método da diérese: “A diérese é a divisão de ideias metodologicamente efetuada. [...] O objetivo da diérese é a definição. Para isso uma ideia genérica (genos) universal, indiferenciada é gradualmente diferenciada até chegar a uma ideia específica indivisa (atmêton eidos). No entanto, aqui se deve observar que Platão ainda não separa terminologicamente espécie (eidos) e gênero (genos). [...] A definição se origina como reunião (synagôgê) de todos os traços distintivos produzidos na diérese; a reunião já é aplicada em cada fase da divisão, quando o gênero é unido com as diferenças anteriores em uma espécie especial e nomeado. Portanto, é a synagogê que 'reúne numa única ideia o multiplamente disseminado'
} 
dois gêneros: arte produtiva e arte aquisitiva. O pescador pertence a esta última. Mas a arte aquisitiva também se divide em duas formas: a troca voluntária e a arte da captura, esta é subdividida em luta e caça, a caça em gênero inanimado e em "caça ao que possui alma e vida" (220a). Esta última se subdivide em caça a seres terrestres e caça a seres aquáticos. Estes podem ser aves marinhas ou animais aquáticos. Os animais aquáticos podem ser caçados de suas maneiras: por cerco (usando redes, laços ou armadilhas) e por vulneração (feridos ou fisgados). Uma última divisão é entre a pesca que fere por meio do arpão (de cima para baixo) ou por meio do anzol (de baixo para cima). Por meio dessa sequência de diéreses, a arte do pescador com anzol é definida.

Em seguida, o paradigma do pescador é aplicado ao caso do sofista. Teeteto e o Estrangeiro concordam que o sofista se assemelha ao pescador pela arte aquisitiva e pela caça. Então, o diálogo retorna na sequência de diéreses ao ponto em que os caminhos se bifurcam, para verificar se dessa forma é possível definir o sofista. O Estrangeiro faz novamente referência à caça aos seres animados, que podem ser terrestres e aquáticos. A caça aos animais terrestres se divide entre os domésticos e os selvagens. O homem é incluído entre os animais domésticos. A caça ao homem pode ser violenta (como a caça aos escravos, a tirania e a guerra) ou pela arte da persuasão. Esta se divide em dois gêneros: a que se dirige ao público e a que se dirige aos indivíduos. Esta última se subdivide naquela que visa o lucro e naquela que ocorre por meio de presentes (como a caça aos amantes). Na caça interesseira, se recebe dinheiro para ensinar a virtude e é nesta última que o sofista é enquadrado. Seguindo o mesmo procedimento, o Estrangeiro tenta definir o sofista como: 1) caçador interesseiro de jovens ricos (a arte da persuasão do sofista é semelhante à caça); 2) negociante, por atacado, das ciências relativas à alma (referente à arte da aquisição);3) pequeno comerciante de primeira e segunda mão (importação espiritual, "negocia discursos e ensinos relativos à virtude", 224d); 4) produtor e vendedor das mesmas ciências; 5) erístico mercenário e contestador (a arte da contestação retórica participa da categoria da luta ou do combate; o sofista é um "atleta do discurso", 231d); 6) o sofista, contraditor (aquele que "purifica a alma das opiniões que são um obstáculo às ciências", 231d).

Assim, o procedimento metodológico seguido por Platão é o de estabelecer um paradigma ou modelo (o pescador) e compará-lo com o tipo-alvo (o sofista). O que os dois têm em comum é a especialização numa certa arte (tekhnê). Então, Platão procede à enumeração e à divisão de diferentes tipos que compartilham

e possibilita a definição; é o complemento necessário da diérese, formando com esta o método da dialética" (Schäfer, 2012, p. 90-91). 
essa qualidade (agricultura, cuidados com os corpos, fabricação de mobiliário, imitação) e os reúne num único nome (arte produtiva). O mesmo é feito em relação ao comércio, à caça e à luta, que são agrupados no gênero de arte aquisitiva. Após a exposição do paradigma, Platão tenta descobrir o que assemelha e o que diferencia modelo e tipo-alvo. Aplicando o método ao sofista, Platão o inclui nos gêneros da caça, da arte aquisitiva (o comércio por atacado e varejista), da arte produtiva, da arte da luta (como atleta do discurso) e a arte da purificação, numa sexta divisão anômala em relação à cinco precedentes. Depois de sucessivas divisões e enumerações, surgem as seis definições do sofista. O Estrangeiro de Eleia, todavia, admite que nenhuma destas definições capta verdadeiramente o que é o sofista. A diérese, com sua série de bifurcações, pode ser visualizada no gráfico abaixo, em que o objeto X é definido por meio de sua inclusão nos gêneros $A^{*}, B^{*}, C^{*}$ e D

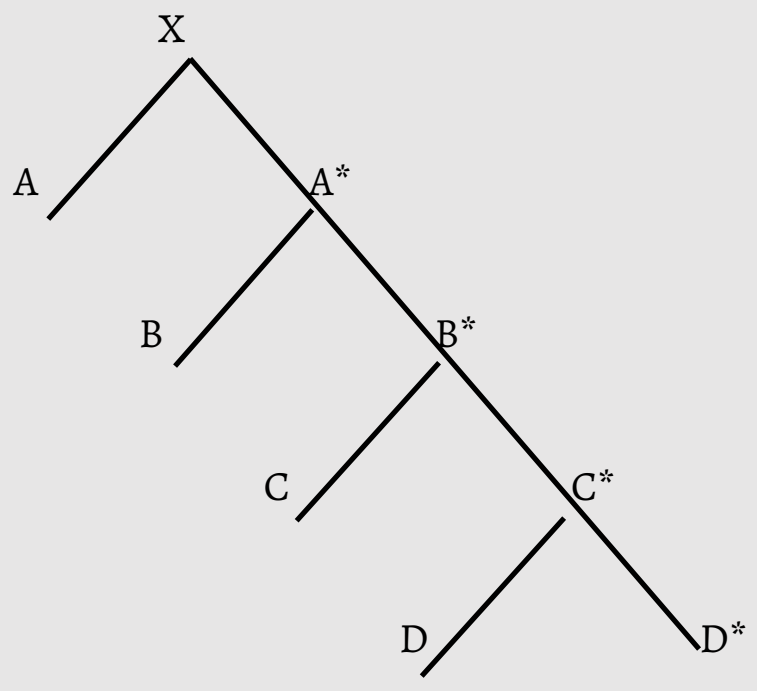

O primeiro paradigma, assim, falha em definir o sofista 3. A essência da pesca com anzol, por ser uma atividade simples e evidente, é facilmente apreendida mediante a diérese. Mas no caso do sofista (ou o gênero sofístico, que é o verdadeiro objeto da investigação), cuja atividade é bem menos evidente e multifacetada, a diérese inicial não dá conta de agarrá-lo. A multiplicidade do sofista revela-

\footnotetext{
${ }^{3}$ O impasse metodológico desse momento do diálogo é assim interpretado por Victor Goldschmidt: “É preciso denunciar a aplicação inadequada do método ou a dificuldade do assunto sempre que se chega a cinco fórmulas diferentes, multiplicidade que, como nos mais belos jogos de imagens, ri do preceito de unificação. É preciso, portanto, mudar de método, ou, segundo a expressão de Teeteto, usar as 'duas mãos' para apanhar o sofista. Recorre-se então a um paradigma, mas que, no final das contas, não unifica nem esclarece as fórmulas anteriores. Comparável às hipóteses predefinicionais dos primeiros diálogos, ele não chega à visão de conjunto, pois nos vemos diante de seis fórmulas e não, como se queria, diante da unificação das cinco primeiras; ele propõe um critério acidental (a arte de purificar) que caracteriza tanto o sofista como o filósofo. E a pesquisa atinge sua primeira 'aporia'” (Goldschmidt, 2014, p. 160).
} 
se um desafio. Em 232a, o Estrangeiro afirma que, devido ao sofista aparentar saber muitas coisas, é difícil encontrar o vértice em que todas as imagens dele coincidam. "Sofista", assim, parece apenas um nome inconsistente (phantasma) para seis atividades distintas.

Para continuar a investigação, em 233d, o Estrangeiro introduz um novo paradigma: a arte da imitação. Uma das definições anteriores forneceu a pista para o novo paradigma. Na sexta definição, o sofista era apresentado como contraditor que aparenta "ter uma sabedoria pessoal sobre todos os assuntos que contradizem" (233c) por sua habilidade de discutir. Assim, o sofista traz "uma falsa aparência de ciência universal" (233d), o que o aparenta à arte da mimética. Na sequência do diálogo, o Estrangeiro proporá uma nova diérese, enumerando cinco definições da sofística que compartilham uma mesma qualidade, a imitação. O exemplo neste caso é o do pintor que, ao produzir imitações homônimas da realidade, é capaz de iludir as crianças pequenas, fazendo-as acreditar que ele poderia igualmente criar a realidade mesma. (234b-c). O sofista faz o mesmo não com pinturas, mas com discursos (logoi), iludindo os jovens "ainda separados por uma longa distância da verdade das coisas" para que acreditem que tudo o que ouvem é verdadeiro e que aquele que fala "tudo conhece melhor do que ninguém" (234c). O Estrangeiro conclui que a sofística é uma arte da imitação e que o sofista apenas simula ser um homem sábio sem a posse efetiva da sabedoria. O sofista é alguém que finge ter conhecimento e que vende conhecimento falso. 4

\section{O PROBLEMA dO NÃO-SER E A FUNDAMENTAÇÃo DO DISCURSO FILOSÓFICO}

Há um problema para demonstrar que o conhecimento do sofista apenas imita o conhecimento verdadeiro: "Que modo encontrar, na realidade, para dizer ou pensar que o falso é real sem que, já ao proferi-lo, nos encontremos enredados na contradição? " (236e). Essa pergunta conduz à parte central do diálogo, em que Platão acerta as contas com a doutrina do ser de Parmênides. Para apresentar o sofista como um especialista em iludir, como alguém que produz falsas aparências por meio de seus discursos, o Estrangeiro tem que demonstrar que Parmênides estava errado. É necessário mostrar que é possível pensar e dizer que, de algum modo, o não-ser é, e dizer isso sem contradição.

\footnotetext{
4 Para chegar a essa conclusão, Platão pressupõe que aceitemos uma premissa importante: que a opinião falsa e a opinião verdadeira de fato possam ser nitidamente distinguidas. Se não se aceitar essa premissa, não é possível afirmar que o conhecimento do sofista é falso ou ilusório.
} 
Para fundamentar a possibilidade do próprio discurso filosófico, é necessário derrubar a tese de Parmênides sobre o ser. Parmênides é considerado o fundador da ontologia e o primeiro a ter proposto o princípio lógico de não-contradição. Seu poema afirma que o princípio (arkhê) é o ser e introduz a célebre tautologia "o ser é e o não-ser não é”. Essa tautologia, tão simples, tem como premissa essencial a identidade entre ser, dizer e pensar, ou seja, entre mundo, pensamento e linguagem. A tese de Parmênides sobre o ser é, portanto, que só o que pode ser dito e pensado verdadeiramente é, enquanto o que não é não pode ser dito nem pensado, consequência que é lembrada pelo Estrangeiro em 238c: "Compreendes então que não se poderia, legitimamente, nem pronunciar, nem dizer, nem pensar o não-ser em si mesmo; que, ao contrário, ele é impensável, inefável, impronunciável e inexprimível?". Se o ser é o oposto do não-ser, então o não-ser não é nada e não podemos nem pensar o nada nem dissertar sobre ele. Se não se pode falar nem pensar o que não é, não há como infirmar o discurso falso, pois nada que é pode ser dito falso. Para tornar possível o discurso filosófico sobre o ser, o Estrangeiro terá que infringir o interdito do "pai" Parmênides, que é enunciado em 237a: "Jamais obrigarás o não-ser a ser; afasta teu pensamento dessa via de investigação”. O Estrangeiro, assim, se depara com o dilema de permanecer fiel à sua herança eleata, mas ao mesmo tempo "matar" o pai Parmênides para tornar possível a comunicação entre ser e discurso, preservando o espírito, mas não a letra do poema de Parmênides. ${ }^{5}$

Isso é feito mediante a formulação da teoria da participação das formas, que pretende resolver o problema da predicação propondo a teoria da comunidade dos gêneros. Entre 242c e 251a, Platão examina as doutrinas mobilistas e imobilistas sobre o ser, para em seguida fundamentar a superação de ambas na doutrina da comunidade dos gêneros. Abel Jeannière identifica os "amigos das formas" com o imobilismo eleático e os "filhos da terra" com o mobilismo heracliteano e afirma que no Sofista o objetivo de Platão é se opor a ambos: aos imobilistas pela afirmação do ser do movimento e aos mobilistas pela afirmação do ser do repouso. O nãoser, assim, se entrelaça com o ser. Não se pode identificar o ser nem ao movimento, nem ao repouso, nem à soma dos dois. Platão quer demonstrar a validade do discurso verdadeiro e universal, mas a tese dos "amigos das formas" sobre o ser torna isso impossível. Para isso, além de repouso e movimento, introduz dois outros gêneros do ser: o mesmo e o outro. O não-ser, assim, não é equivalente ao nada, mas pode-se dizer que é alteridade:

\footnotetext{
5 “O Estrangeiro não nega sua herança eleata. Se, como um parricida, ele 'mata' a lógica homogeneizante de Parmênides sem negar o princípio de não-contradição, ele o faz para preservar o que de mais importante recebeu de Parmênides, o princípio da discursividade do ser, que, revisado, permite uma relação não conflituosa entre discurso e ser. Com a reformulação dos dois princípios eleatas, o Estrangeiro garante a possibilidade de que o próprio poema de Parmênides possa ser enunciado a partir da concepção referencialista do discurso, possibilidade esta que é comprometida quando se extraem as consequências discursivas da lógica e da ontologia de Parmênides.” (Souza, 2006).
} 
Mas esse ser, que permite ou não permite uma composição dos gêneros, que é o outro, que é a diferença, mas não exclui o mesmo, nunca pode ser integrado nem a um gênero nem ao conjunto dos gêneros. O ser não tem contrário. O ser não é nada de estático, nada de dinâmico, nada de diferente, nada de idêntico. Ele é "potência de comunidade" (Jeannière, 1995, p. 105).

Segundo Souza, a ontologia eleata não é abandonada, mas reformulada por Platão, que tenta garantir a "potência de comunidade" do ser mediante o entrelaçamento dos cinco gêneros e a doutrina da participação das formas umas nas outras:

Platão propõe uma ontologia na qual ser e não-ser deixam de ser excludentes. Ao contrário, o não-ser passa a ser um constituinte do ser de cada coisa. O princípio de não-contradição eleata é, de certo modo, reformulado por Platão: o não-ser não é o contrário do ser; é um ser outro que está em contraste com o ser (Souza, 1997, p. 86).

Santos, igualmente, reconhece que essa reformulação da ontologia eleática é necessária para tornar possível o discurso filosófico sobre o ser:

Ao fragmentar a unidade monolítica do ser de Parmênides, ao conferir cidadania ontológica ao não-ser, enfim, ao atribuir à realidade uma estrutura essencial determinada, o Estrangeiro não faz mais que traduzir ontologicamente exigências lógicas que encontra implicadas no conceito de discurso racional sobre o ser (Santos, 1996, p. 7)

Um outro motivo pelo qual é indispensável reformular a ontologia parmenidiana é que esta cria um refúgio cômodo para os sofistas, que suprimem a diferença entre o falso e o verdadeiro e confundem conhecimento com opinião. O sofista Protágoras foi o primeiro a afirmar que coisas diferentes podem ser verdadeiras para pessoas diferentes. Protágoras entendia a verdade como relativa ao sujeito: algumas coisas são "verdadeiras para você", outras "verdadeiras para seu melhor amigo" ou "verdadeiras para seu pior inimigo"; algumas coisas podem ser verdadeiras para mim hoje, mas não serem mais amanhã ou no ano que vem, como se eu fosse um ser diferente a cada momento. Nada é simplesmente verdadeiro; as coisas são sempre para você como parecem ou segundo seu ponto de vista (Nagel, 2014, p. 10-11). Esse relativismo ontoepistemológico torna impossível o discurso verdadeiro sobre o ser porque se toda verdade é parcial e relativa ao sujeito, ninguém nunca pode estar errado.

\section{A SOFÍSTICA COMO FALSA DIALÉTICA E A DEFINIÇÃo dO FILÓSOFO}

Por intermédio do entrelaçamento (symplokê) e da mistura (meixis) entre formas diversas, a teoria da participação garante a comunicação entre as formas e a relação lógico-linguística de predicação. O ser não tem contrário, mas deve ser concebido de modo relacional: 
Há uma associação mútua dos seres. O ser e o outro penetram através de todos e se penetram mutuamente. [...] O ser, participando do outro, será, pois, outro que não o resto dos gêneros. Sendo outro que não eles todos, não é, pois, nenhum deles tomado à parte, nem a totalidade dos outros, mas somente ele mesmo; de sorte que o ser, incontestavelmente, milhares e milhares de vezes é, e os outros, seja individualmente, seja em sua totalidade, são sob múltiplas relações e, sob múltiplas relações não são (259a-b).

Resta, então, definir a natureza do discurso e fundamentar a separação entre a opinião falsa e o discurso verdadeiro sobre o ser. A partir de $260 d$, o Estrangeiro retoma o fio da definição do sofista. A tese dos eleatas sobre o ser criava um refúgio cômodo para o sofista, pois se o não-ser não pode ser dito ou enunciado, se não tem nenhuma participação no ser, não há opinião ou discurso falso. Porém, se o não-ser não é o oposto do ser, mas dele participa sob múltiplas relações, é possível demonstrar a existência da falsidade. Se o verbo ser é interpretado como cópula, ligando sujeito e predicado, ao invés de uma relação de identidade absoluta, pressuposta pelo poema de Parmênides, então "pensamento, opinião e imaginação são gêneros suscetíveis, em nossas almas, tanto de falsidade como de verdade" (263d).

A partir de 264c, o Estrangeiro retoma a diérese para chegar à definição final do sofista. A arte da produção, na qual se inclui a arte mimética, pode ser dividida em arte divina e arte humana. Cada uma delas se subdivide em duas. A arte divina produz realidades e simulacros (como os sonhos e as imagens criadas pela luz e pela sombra). A arte humana se divide igualmente entre a produção da coisa e da imagem da coisa (como o arquiteto que cria a casa e o pintor que representa uma casa) A produção de imagens, por sua vez, subdivide-se em dois gêneros: a produção de cópias e de simulacros. Estes podem ser fabricados por meio de instrumentos ou quando a própria pessoa se presta como instrumento (mímica ou imitação). A imitação se divide entre os que conhecem o objeto imitado e os que o imitam sem conhecê-lo. É o caso daqueles que simulam qualidades como virtude e justiça, imitando-as em atos e palavras, sem as possuírem realmente. Conhecimento e não-conhecimento são essenciais para distinguir as duas formas de imitação; o Estrangeiro propõe o nome de "mimética sábia" à primeira e "doxomimética" à segunda. Como o sofista não é alguém que sabe, mas alguém que apenas imita, ele deve ser subsumido sob a doxomimética. Resta ainda mais uma divisão a fazer. Entre os imitadores sem conhecimento há os ingênuos, que confundem ciência com opinião, acreditando ter ciência quando só têm opinião, e os imitadores irônicos que têm consciência de sua ignorância mesmo sobre assuntos que afirmam saber. Estes últimos ainda se subdividem entre os que praticam a ironia em longos 
discursos públicos ou em reuniões privadas e breves argumentos, obrigando o interlocutor a se contradizer. O primeiro é identificado ao político ou orador popular e ao segundo caberia o nome de sábio ou sofista. Como se estabeleceu antes que o sofista não tem sabedoria real, mas apenas simula possuir sabedoria, o nome adequado é realmente sofista. Assim se encerra o diálogo, unificando todos os traços previamente levantados à unidade do nome do sofista.

Mas como o sofista se diferencia do filósofo? Logo no início do diálogo, em 216d, Sócrates aponta para a questão da definição do filósofo, que seria objeto de um terceiro diálogo, além do Sofista e do Político, não escrito por Platão. Em 243e, a definição do filósofo é retomada. Aqui o filósofo é definido como aquele que possui a ciência dialética que permite a orientação através do discurso para discriminar os gêneros que concordam e que não concordam e como cada um participa ou não do outro por meio do método das hipóteses e das divisões. Teeteto afirma que essa não é somente uma ciência necessária, mas a "suprema ciência" (epistémes megístes) (253C). A dialética é a "ciência dos homens livres" e ensina a "dividir por gêneros, e não tomar por outra, uma forma que é a mesma, nem pela mesma uma forma que é outra" (234d). Enquanto o sofista se refugia na "obscuridade do nãoser", o filósofo dirige seus raciocínios à "forma do ser" e em virtude do "resplendor" do ser, que o filósofo investiga, ele também não é fácil de apreender "pois os olhos da alma vulgar não suportam a contemplação das coisas divinas" (254b, referência à alegoria da caverna e à incompreensão que o filósofo sofre ao tentar libertar da ignorância os prisioneiros no interior da caverna).

O filósofo se assemelha ao sofista e se distancia dele em certos aspectos, de forma semelhante à defendida pela teoria da participação das formas. Como o sofista, o filósofo não possui sabedoria, porém diferente do sofista ele não simula possuí-la. Tal como o sofista, o filósofo utiliza o método de perguntas e respostas e examina as razões do interlocutor para captar suas contradições, porém o objetivo dessa atividade é distinto nos dois casos. A dialética é a arte do diálogo em que cada interlocutor é levado a admitir sua própria ignorância para, assim, engajarse no caminho que conduz à sabedoria. A erística do sofista, em contrapartida, visa apenas contradizer para vencer o debate. Podemos dizer, portanto, que a sofística é uma falsa dialética pois não forma nem transforma o sujeito que dela participa. Não é, portanto, verdadeiro diálogo, mas apenas técnica habilidosa visando impor o interesse de cada interlocutor. O diálogo, por sua vez, pressupõe que cada interlocutor abra mão de seu interesse particular em nome da verdade, o bem e a justiça. 


\section{CONCLUSÃO}

Por sua discussão da questão do não-ser e por sua intenção de fundamentar o discurso filosófico, o diálogo Sofista ocupa uma posição central na história da filosofia. Seu exame da relação entre ser e linguagem ainda é um tópico de grande importância em filosofia da linguagem e ontologia. A relevância da questão é assim apresentada por Pierre Aubenque:

O debate sobre as relações da sofística com a linguagem em geral, com o discurso filosófico em particular, não é somente o envoltório da discussão central sobre o ser e o não-ser; essa discussão é um dos lugares, de forma nenhuma fortuitos, nos quais se constituiu o que os autores do século XVII não acreditavam denominar tão bem chamando-o "onto-logia", discurso sobre o ser, discurso do ser, articulação do ser e do discurso, cuja unidade problemática deve ser busca do lado do que já Parmênides designava como o "pensamento". O Sofista é de fato, em toda a acepção do termo, um texto central, tanto para o platonismo quanto para a história da filosofia (Aubenque, 1991, p. 12).

Uma tradição anti-platônica que se origina em Nietzsche pôs em questão a solução de Platão para o problema do discurso falso e repropôs a posição dos sofistas em outros termos. Certas correntes do pós-modernismo e do pragmatismo contemporâneos defendem a visão relativista de que a verdade é apenas uma construção cultural ou social e que não há nenhum critério objetivo e seguro para separar doxa e epistême. Por trás das idealidades universais da dialética platônica (a verdade, o bem, a justiça, a virtude etc.), essas correntes denunciam os interesses e os jogos de poder que particularizam identidades e dividem o mundo em grupos dominantes e dominados. Porém, se não houver nenhum critério para distinguir mera opinião de conhecimento verdadeiro, em outras palavras, se todo conhecimento for apenas guerra de narrativas e toda tese apenas a expressão de uma "identidade" particular, não há mais base normativa para fundamentar nossas práticas e instituições ou mesmo para fundamentar um projeto de transformação da sociedade. Se a verdade não existe (ou se tudo é verdadeiro, para retomar a tese de Protágoras), perdemos igualmente os meios para denunciar as fake news, teorias da conspiração e "verdades alternativas" que tanto dano têm causado a nossas democracias. Por isso a leitura de Platão ainda é essencial nos dias de hoje. Sua concepção dialógica da filosofia é de suma importância numa sociedade cada vez mais conflituosa e fragmentada, em que os sujeitos tendem a se enclausurar em visões de mundo fechadas (e, portanto, dogmáticas) como mônadas incomunicáveis. A arte dialética que ensina a nos colocar no lugar do outro, a aceitar as limitações de nossos próprios pontos de vista para engajar-nos no diálogo e a deliberar sem prejuízos com base no discurso racional para solucionar nossos problemas é exatamente o phármakon de que o mundo atual desesperadamente carece. 


\section{REFERÊNCIAS}

AUBENQUE, Pierre (dir.). Études sur le Sophiste de Platon. Paris: Vrin, 1991.

CHAUI, Marilena. Introdução à história da filosofia 1: Dos pré-socráticos a Aristóteles. São Paulo: Companhia das Letras, 2002.

GILL, Mary-Louise, "Method and Metaphysics in Plato's Sophistand Statesman", The Stanford Encyclopedia of Philosophy(Spring 2020 Edition), Edward N. Zalta (ed.), URL = $<$ https://plato.stanford.edu/archives/spr2ozo/entries/plato-sophstate/>.

GOLDSCHMIDT, Victor. Os diálogos de Platão: Estrutura e método dialético. São Paulo: Edições Loyola, 2014.

GOLDSCHMIDT, Victor. Tempo histórico e tempo lógico na interpretação de sistemas filosóficos, in: GOLDSCHMIDT, Victor. A religião de Platão. São Paulo: Difusão Europeia do Livro, 1970, p. 139-147.

HADOT, Pierre. O que é a filosofia antiga? São Paulo: Loyola, 1999.

JEANNIÈRE, Abel. Platão. Rio de Janeiro: Zahar, 1995.

NAGEL, Jennifer. Knowledge: A very short introduction. Londres: Oxford, 2014.

PLATÃO. Sofista In: Os Pensadores III. Platão: Diálogos. Trad. Jorge Paleikat e João Cruz Costa. São Paulo: Abril Cultural, 1972, p. 137-203.

SANTOS, Luiz Henrique Lopes dos. A harmonia essencial. In: NOVAES, Adauto (Org.). $A$ crise da razão. São Paulo: Companhia das Letras, 1996, p. 437-455.

SCHÄFER, Christian (Org.). Léxico de Platão. São Paulo: Loyola, 2012.

SOUZA, Eliane C. de. Sobre a teoria da participação das formas no Sofista de Platão. HYPNOE, Ano2 / No. 3, p. 81-88.

SOUZA, Eliane C. de. Ser e linguagem em Platão In: SOUZA, Eliane C. de.; CRAIA, Eládio C. P. (Org.). Crítica e Hermenêutica. Cascavel: Edunioeste, 2006. 